\title{
Understanding the Ideal Qualities of a Life Plan Community
}

\author{
Jeffrey S. Smith, Abigaile Molzer \\ Kansas State University, Department of Geography and Geospatial Sciences, Manhattan, Kansas, USA \\ Email: jssmith7@ksu.edu
}

How to cite this paper: Smith, J. S., \& Molzer, A. (2020). Understanding the Ideal Qualities of a Life Plan Community. Current Urban Studies, 8, 305-319. https://doi.org/10.4236/cus.2020.82017

Received: April 30, 2020

Accepted: June 5, 2020

Published: June 8, 2020

Copyright $\odot 2020$ by author(s) and Scientific Research Publishing Inc. This work is licensed under the Creative Commons Attribution International License (CC BY 4.0).

http://creativecommons.org/licenses/by/4.0/

\section{(c) (i) Open Access}

\begin{abstract}
Baby Boomers have impacted American society at every stage in their life. As the Silver Tsunami approaches advanced age, they are faced with numerous elder care options. Two of the most popular are aging in place and living in a Life Plan Community (LPC). Known for their spectrum of services, LPCs are purported to offer a better quality of life, especially for individuals living in urban settings. Existing research, however, has yet to ask residents what specific beneficial characteristics and qualities within an LPC enhance their life. Drawing upon data collected through informal interviews and a focus group discussion $(\mathrm{n}=31)$, residents reveal an appreciation for the can-do spirit augmented by close personal relations. They also cherish opportunities for personal growth built upon the individualized care that enables them to maintain their autonomy. The findings will assist a host of individuals (e.g. retirees, Adult Child Influencers, developers, city planners) to make appropriate planning decisions.
\end{abstract}

\section{Keywords}

Life Plan Community, Continuous Care Community, Quality of Life, Baby Boom Population, COVID-19

\section{Introduction}

The Baby Boom cohort has had a profound impact on American society. At each major stage in their life cycle the boomers have inspired, initiated, or instigated significant changes in U.S. culture (Frey and DeVol, 2000), from normative behavior and gender roles to music and social relations ${ }^{1}$. In 2011, the oldest baby

${ }^{1}$ Over the course of 19 years (1946-1964), 76 million babies were born in the U.S. When baby boomers were infants the diaper industry met the demand for greater convenience by introducing disposable diapers. As the boomers reached school age, cities built thousands of new schools. In the 1960s the "Me Generation" led the social revolution advocating for racial and gender equality. When the boomers reached middle age and experienced changes in their body chemistry (e.g. declining testosterone levels), the pharmaceutical industry responded by concocting little blue pills. More recently, muscle cars (e.g. Chevy Camero, Dodge Charger, and Ford Mustang), reminiscent of those produced in the 1960s, have made a comeback in popularity. 
boomers began reaching retirement age and they are disrupting the country with a new set of needs and demands.

Based on actuary data, in approximately 15 years, the leading edge of the baby boom population, in conjunction with their Adult Child Influencers (ACIs), will begin searching for care facilities to attend to their needs in older age (Colby and Ortman, 2014). They will have several options including adult day care, intergenerational living, and accessory dwelling units (a.k.a. Granny Units).

One option gaining widespread appeal is aging in place. According to AARP (2012), nearly 90 percent of retirees would prefer to live in their current home as they age. The rapid growth of in-home care services is affording seniors the opportunity to live a safe, happy, and healthy life in older age (Senior Living, 2019). Although research suggests that individuals who live in their private home preserve their independence and maintain strong community connections (USC, 2019), many are prevented from realizing this option because of life circumstances and the degenerative aging process.

An alternative option is to reside in a Life Plan Community (LPC). LPCs are age-restricted communities designed to be the "final move". This model caters to independent older adults by offering a continuum of living arrangements with an increasing spectrum of services, health care option, and amenities that support ongoing physical health, social engagement, and a sense of community (Ayalon and Green, 2012; Leary et al., 2019). LPCs are particularly common in urban settings. Gerontology experts predict this option will fit well with baby boomers because they "are expected to bring increased demands for flexibility and choice, while expecting that their input will be valued and acted upon" (Mckenzie and Schweiger, 2018: p. 3).

Existing literature affirms that individuals residing in LPCs experience a superior quality of life including health and wellness benefits, but what has yet to be fully understood is the specific beneficial characteristics and qualities of these facilities. Lacking are empirical studies that examine the attributes of LPCs from the residents' perspective. The purpose of this article is to expose what specific elements enhance residents' quality of life and foster a strong sense of community.

\section{Background: Seeking a Good Quality of Life}

The stereotypical image many people have of nursing homes is an institution where individuals are parked in wheelchairs on the margins of a public gathering space, or in front of a blaring television, in an air filled with a mixture of urine and cleaning solutions. The worst of these facilities are characterized as places where people go as they wait to die (Jones, 2019). These procedure-driven facilities are places where individual desires take a back seat to efficiency and standardized protocols (Fox et al., 2005). "You' re not going to put me in one of those homes" is a common refrain heard in households throughout the country.

There are both high-quality and less reputable elder care facilities across the country. With the intention of ensuring the overall quality of care among all 
$16,500+$ facilities, the U.S. federal government has steadily increased its regulatory oversight of elder care facilities. Nursing homes have become the most regulated industry in the U.S. after nuclear power plants (Steinberg, 2018). Increasingly, aging in place is regarded as a more attractive alternative.

Because one's home is commonly seen as a physical extension of one's self (Blunt, 2005; Smith, 2018), aging in place (living out one's life in their private home) accrues all sorts of benefits. The literature indicates that aging in place contributes to greater physical activity, continued individual autonomy, enduring self-confidence, retained self-identity, and sustained mental health (Gilleard, Hyde, and Higgs, 2007; Lecovich, 2014; Oswald et al., 2010; Thomas and Blanchard, 2009). Since baby boomers are wealthier and more physically fit than previous generations (Mckenzie and Schweiger, 2018), aging in place appears highly desirable.

According to AARP (2012), although an overwhelming majority of older individuals would prefer to remain in their own home, aging in place (however beneficial) is not a viable option for most people. In fact, 57 percent of individuals 70+ years of age indicated that living independently is a struggle (AARP, 2012) and can still lead to feelings of loneliness, helplessness, and boredom (Oswald et al., 2010). Moreover, 20 percent of people in their advanced ages said they could not perform daily tasks (e.g. bathing) without assistance (AARP, 2012). An even bigger concern is how well the physical properties of a private home can accommodate an individual's diminishing physical abilities. Navigating some physical obstacles (e.g. stairs, bathtub) can quickly turn into life-threatening situations. In the end, aging in place can cause more harm than good.

As Thomas and Blanchard (2009) indicate, "our [society] has constructed a continuum that positions institutional long-term care at one end of the spectrum, and an idealized vision of aging in place at the other. The challenge is to escape this false choice" (p. 13). In recent years, an increasing number of older folks are residing among a community of active adults who are supported by a continuum of care and services. Various names have been attached to such communities including Transition Living Arrangements, Leisure-oriented Retirement Communities (LORCs), Continuing Care Retirement Communities (CCRCs), and most recently Life Plan Communities (Kennedy and Coats, 2008; Lecovich, 2014), but at the core of these communities is the preservation of individual autonomy. The generation known for burning bras and protesting social injustice is particularly predisposed to living in such a community. According to Thomas and Blanchard (2009), "[Baby Boomers] lived together, in a variety of household settings with friends who shared the daily rhythms of life and who really cared for one another. Boomers bonded in ways unheard of by their parents with unrelated people outside their families" (p. 15). A study by MetLife (2011) found that one-third of boomers were interested in living in a "clustered living community" with a variety of shared amenities (e.g. dining room, library, laundry). 
LPCs are places that enable older individuals to live in the same campus complex as their life situation changes. People typically enter the community through an Independent Living arrangement and as their mental and/or physical abilities wane, they transition to Assisted Care. LPCs offer varying levels of independent living accompanied by a continuum of personal assistance and services.

In recent decades a variety of scholars have identified elements that lead to a happy, healthy life. In 1976, William Hettler (1976) listed five dimensions of wellness: physical, social, intellectual, occupational/vocational, and spiritual. According to the National Wellness Institute which Hettler co-founded, these elements sustain older individuals and contribute to a positive quality of life. In 2005, a team of twelve experts representing many of geriatric's leading institutions (e.g. The Eden Alternative, Action Pact, Pioneer Network, Wellspring) identified six domains of personal well-being including: positive self-identity, continuing personal growth, individual autonomy, safety and security, interpersonal connectedness, and a meaningful life (Fox et al., 2005).

As our understanding of what elements lead to a good quality of life improves, scholars have begun assessing how the qualities and characteristics of LPCs meet the various dimensions of wellness and/or personal well-being. In 2003, for example, Krout and Wethington (2003) examined how differing types of residential space impact quality of life among retirees. Likewise, Kennedy and Coates (2008) explored the connection between resident satisfaction and five domains (built environment, financial environment, service delivery, social opportunities, and spiritual support). Others have focused on social integration after moving into a LPC (Erickson et al., 2000; Ayalon and Green, 2012) and comparisons of quality of health and wellness among LPC residents (Marx et al., 2011; Bohle et al., 2014; Roberts and Adams, 2018). In 2018, the Mather LifeWays Institute on Aging began one of the industry's most ambitious studies of LPCs. The five-year, longitudinal study assesses "the health and [overall] wellness of LPC residents" and identifies "what organizational characteristics are associated with resident wellness outcomes" (e.g. profit status, fee structure, religious affiliation, neighborhood area type, number of amenities) (Leary et al., 2019: p. 17).

Despite the growing body of literature that assesses the attributes of LPCs, there is a dearth of research on what specific characteristics and qualities give residents a favorable quality of life. Lacking is qualitative, empirical studies that ask residents to indicate what elements foster feelings of contentment and satisfaction in an LPC. This article seeks to help fill that gap in the literature. Next, we discuss our research methods. This is followed by the presentation of our research findings. With a conscious effort to build upon existing literature, we structured our findings around four of Fox et al.'s (2005) domains of personal well-being.

\section{Methods}

This study is timely because the oldest baby boomers are about 15 years away 
from needing personalized assistance in older age. We selected a qualitative approach to data collection because it effectively captures the thoughts and opinions of key informants. Among the qualitative methods at our disposal (Creswell, 2013), we employed the case study approach because it enabled us to gather detailed information on a small, specific group of people. The main benefit is that it gives a central voice to the residents. Our data collection centered on semi-structured interviews with 15 volunteers who represented a cross section of the resident population (e.g. various ages and length of time in residence) (Table 1).

After acquiring IRB approval in November 2018, we sat down with each individual and talked about their experience living in a LPC ${ }^{2}$. We approached each of the 90-minute interviews with a set of standardized questions (Table 2) which guided our conversations ensuring that we consistently addressed specific themes. However, the relaxed, fluid nature of the informal interviews allowed us to also explore tangential information. We recorded each interview and transcribed the conversations for further content analysis.

After completing the interviews, we presented the preliminary results to a general audience at the LPC. Sixteen individuals (11 females) attended our presentation. We then, engaged in a 50-minute focus group discussion with those individuals to attain additional feedback and insight. Our overall sample size was small $(n=31)$, however small sample sizes are common in a case study

Table 1. Profile of Interview Respondents $(n=15)$.

\begin{tabular}{ccccc}
\hline Pseudonym & Age & $\begin{array}{c}\text { Marital } \\
\text { Status }\end{array}$ & $\begin{array}{c}\text { Years in } \\
\text { Residence }\end{array}$ & $\begin{array}{c}\text { Type of Living } \\
\text { Arrangement }\end{array}$ \\
\hline Bill & 94 & Married & 13 & IL \\
Bob & 83 & Married & 4 & IL \\
Esther & 79 & Widowed & 8 & IL \\
Harriet & 82 & Widowed & 14 & IL \\
Jan & 92 & Married & 13 & SN \\
Joan & 83 & Married & 4 & IL \\
Jim & 95 & Married & 7 & IL \\
John & 83 & Married & 4 & IL \\
Kay & 81 & Widowed & 12 & IL \\
Ruth & 84 & Widowed & 3 & AC \\
Robert & 77 & Widowed & 4 & IL \\
Sandra & 85 & Married & 13 & IL \\
Steve & 88 & Married & 13 & IL \\
Yvette & 95 & Married & 7 & IL \\
Yvonne & 82 & Married & 4 & IL \\
\hline
\end{tabular}

Notes: ${ }^{\star}$ Used to ensure anonymity of respondents; IL = Independent Living; AC = Assisted Care; $\mathrm{SN}=$ Skilled Nursing.

${ }^{2}$ All of the individuals we consulted reside at Meadowlark Hills Retirement Community in Manhattan, Kansas, USA, 66,502. In full disclosure, Dr. Smith has served on the Board of Trustees of M.H.R.C. since 2013 which has granted him additional perspective on the retirement community. 
Table 2. List of semi-structured interview questions.

\footnotetext{
1. Demographic information (e.g. age, gender, educational attainment, marital status, Profession, number of children, distance to nearest relative).

2. How long have you lived at MHRC? Current and past type of living arrangement?

3. What specific factors influenced your decision to move to MHRC?

4. What is your overall level of satisfaction living at MHRC? Likes/dislikes?

5. What factors influenced where you decided to live at MHRC?

6. What aspects of life have been most influential in your experience at MHRC?

7. Can you talk about some of the services/amenities/care offered at MHRC?

8. In what ways have you engaged in programs/services/amenities at MHRC?

9. What other things/qualities do you think are important for me to know about as I gather information about living at MHRC?

10. How has what you heard prior to moving to MHRC compared to your experience living at MHRC?
}

approach, especially when in-depth information from a cross-section of individuals is obtained (Fusch et al., 2017). The data enabled us to assess what qualities within an LPC enhance residents' quality of life and personal well-being.

\section{Results}

An entire industry of self-help books, not to mention professional therapy, speaks to the countless ways people strive to achieve contentment and personal happiness. In 2005, Fox et al. released a comprehensive model that identifies the seven domains of personal well-being and overall happiness among the elderly. Drawing inspiration from their model, we use four of their elements (individual autonomy, safety and security, interpersonal connections, and continuing personal growth) as an organizational structure to report our findings.

\subsection{Individual Autonomy}

Social scientists define agency as an individual's capacity to act independently and the freedom to make one's own choices (Emirbayer and Mische, 1998). From an early age an unwritten goal in life is to make our own decisions. This is best illustrated when considering the antics of two-year-old toddlers or the disturbing behavior of teenagers who defy their parents. A hallmark of being an adult is having the autonomy to make decisions for oneself. Reaching older age should not strip a person of agency. According to Fox et al. (2005), personal well-being and happiness are ensured when older individuals can make their own choices and live with the consequences.

It was revealing to learn that maintaining individual autonomy (agency) is the most important quality of living in an LPC. The residents we talked with indicated that every aspect of residents' life is self-directed; people make their own decisions. The continuum of care offered at an LPC further enables individuals to live an independent life without sacrificing safety. At a basic level, LPCs offer light household cleaning, room service, and concierge service. As an individual's 
functional independence deteriorates, the LPC provides more assistance including a full meal plan, laundry service, and skilled nursing care. As Esther indicated, "if you want structure and assistance you can get it, if you don't, you don't have to". One of the most meaningful services mentioned by respondents is the Companion Program which pairs residents with a nurse or volunteer who serves as the individual's personal assistant. As Ruth said, "I am almost totally independent except for meals and bath[ing] and that kind of thing. It's really great to have a companion available if I need it'. Individualized schedules and personal attention undoubtedly make caring for people more complex, but residents place high value on retaining their individual autonomy. Successful LPCs empower individuals to make their own decisions and hold them responsible for their own health and life trajectory. Individual autonomy is a fundamental aspect of an individual's personal well-being.

\subsection{Safety and Security}

As Abraham Maslow tells us, once our most basic needs (e.g. food, shelter, warmth, rest) are met, the next higher set of needs for human existence is safety and security. To realize our full potential, we must live in an environment where our physical existence is assured, our daily activity space is stable and predictable, and our individual privacy is respected.

As people reach advanced age, however, they become vulnerable; their physical capacity diminishes, and their safety and security become increasingly compromised (Fox et al., 2005). It is not difficult to imagine how an older person feels when their house and neighborhood no longer feels safe and secure. It is important to note that feelings of safety and security include both the physical conditions a person lives in as well as their emotional peace of mind.

Topping the list of reasons why living in an LPC affords residents strong feelings of safety and security is the availability of on-site, quality health care. According to the residents we talked with, the only place perceived to offer better security in health care is a hospital. Many individuals said that they derive considerable comfort and an immeasurable sense of security knowing that doctors, nurses, and aids are on hand to attend to their health care needs on a moment's notice. The safety and security of living in an LPC has become particularly apparent during the COVID-19 pandemic. Furthermore, knowing that your parent is enveloped by high quality care also gives Adult Children Influencers (ACIs) a considerable peace of mind.

Along the same lines, the continuum of care offered at a LPC significantly adds to feelings of safety and security. As Bob told us, “... everyone's path in life is different. Some of us get old quicker than others and need more help. Others are sturdier and can take care of themselves longer. When my spouse got to the point where she needed help with her Alzheimer's, I was so relieved to be [in a $L P C]$. She could go into specialized care and treatment and I could stay in our apartment'. Bob's story was echoed repeatedly by others. The multitude of care 
options offered at a LPC ensures that couples remain geographically close, rather than being separated at different facilities. The benefits of being under the same umbrella of care give residents a considerable peace of mind and great sense of security.

One of the most impressive aspects found at many LPCs is the specialized care including memory care programs and Parkinson's programs. Residents told us that having such care in-house gives them a strong sense of security. At an LPC individuals are given the highest level of individualized care in a setting they are familiar with. As residents explained in a multitude of ways, living in an LPC wraps them in a safe bubble (a safety net).

\subsection{Interpersonal Connections}

It has long been known that individuals who maintain strong interpersonal relations with others tend to live happier, healthier, and longer lives (Harvard Health, 2019). Close social ties not only help reduce stress and aid in physical healing, but also lowers blood pressure, reduces the risk of cardiovascular disease, and delays the onset of dementia (Advent Health, 2019; Qualls, 2019). Interpersonal connections are much more complex than simply maintaining healthy relationships with family and friends. It also centers around belonging to a larger community of people.

For decades social psychologists, have tried to understand and define sense of community. The term refers to a feeling of collective experience and common identity among a group of people. In the 1970s scholars began identifying the elements that contribute to the formation of a sense of community including length of time in residence, personal connections to neighbors, and level of satisfaction within a group (Brodsky and Marx, 2001; Glynn, 1981; Long and Perkins, 2003). An impressive contribution comes from David McMillan and David Chavis who pinpoint four key elements of a strong sense of community. Two are particularly relevant to our article including membership and social interaction (McMillan and Chavis, 1986).

According to McMillan and Chavis (1986), membership refers to how welcome individuals feel within a community or group. They explain that once an atmosphere of trust is established, individuals must come to feel like legitimate members of the community by having their presence reinforced as well as their thoughts and actions rewarded. McMillan and Chavis (1986) explain that social interaction refers to the positive and rewarding feelings that members have when they are involved in group activities. As individuals interact with others and cultivate personal relationships, they develop strong emotional connections to the community.

Among the residents we interviewed, interpersonal connections were as important to their happiness and quality of life as individual autonomy and feelings of safety and security. Without exception, the residents said that their relationships with others were on par with those they have with family members. As Bob 
indicated, "[The personal relations] create the greatest value and meaning here [at the LPC]. Yes, all the services and activities are great, but it's the fact that you can have these personal connections, friendships, that really make it work to a very satisfying degree".

Successful LPCs invest considerable time and resources to create an environment that fosters strong interpersonal relations. For example, residents said they appreciate the staff hosting dinner parties, special social events, and holiday celebrations. Residents see these not as job-related formalities, but as genuine celebrations for everyone. Furthermore, there are various organized outings that promote socialization including local entertainment (e.g. museums or live performances) and multi-day trips (e.g. Omaha, Chicago, and Apostle Islands National Park).

Probably most important are the support groups. Individuals who are dealing with personal grief, a spouse with memory care challenges, or terminal illnesses are all able to connect with a supportive community of people. For example, Robert (a resident whose wife passed away from Alzheimer's) describes the memory care support group: "we have the spouses of these persons that have the disease ... We talk about coping mechanisms, what we do, and how we can help them. The social support has been so valuable to me that I still go to those meetings even though Sue is no longer here." By connecting people who have similar difficulties, the LPC ensures that everyone is taken care of and has a community to lean on.

The residents we interviewed indicated that interpersonal relations and social connections extend beyond fellow residents. The office personnel, and health care professionals are not just staff workers or caregivers, but rather friends and confidants. With his wife living in skilled nursing, Jim reflected on his relationships with staff: "P ve gotten really well acquainted with many of the staff members and there's some really interesting people working here. I view them as friends and that is a scenario in which I find some real satisfaction and meaning".

One of the best examples of interpersonal relations between residents and staff centers on the Companion Program (explained above). In today's fast-paced world programs like this seem to make a lot of sense. Elderly parents who do not want to depend too heavily on their adult children have viable alternatives. Residents are alleviated from that stress because the Companion Program is like having a relative there without the worry of burdening them. Ruth's situation is a perfect example. As she explained, "since everybody that's in my family is working every day, I don't want them to have to change their [daily schedule] to take me to an appointment or something. That's what the Companion Program is for". The program matches residents with someone they know and trust who can fill in when family members are not available. Clearly, close relationships with employees are just as important and rewarding as the friendships people develop with other residents. 
Through our interviews it became abundantly clear that interpersonal connections are what sets LPCs apart from other advanced-aged living arrangements. Residents develop close ties with each other as well as staff. One resident who wished to remain anonymous indicated that when she was living in her private home, life was so routine and boring. Even though she volunteered twice a week within the community, she felt isolated from the world around her; she never felt a level of personal satisfaction and contentment. After moving to the LPC, her life has become so much more rewarding. They (she and her husband) are constantly surrounded by friends and there is always something stimulating to do.

\subsection{Continuing Personal Growth}

One criticism of aging in place is that individuals lack intellectual stimulation and opportunities for personal growth (Marx et al., 2011). In fact, a common lament among elderly people living in their private homes is the feelings of isolation and a lack of personal growth opportunities. And yet, a growing body of literature (Apóstolo et al., 2014; Morley et al., 2014) asserts that the human mind has the capacity to continue growing and expanding even when our corporeal abilities wane. Moreover, feelings of personal well-being and contentment are strongly tied to the process of growth and achievement. Realizing one's full potential should not stop just because a person has reached an advanced age.

According to the residents we talked with, one of the most rewarding elements of their LPC is the pervasive "can-do spirit". Residents, regardless of abilities, are treated as vibrant, individuals who thrive on continual growth. Nearly everyone told us how much they value the opportunities they have for personal growth. John captured the essence of this when he said, "The most important single thing that stands out is the positive atmosphere around here. It's all about living, staying active, staying involved in things". Effective LPCs provide a multitude of opportunities for both intellectual and physical achievement.

Intellectually, successful LPCs partner with nearby community services (e.g. college, library) to offer continuing education classes. The residents we talked with indicated that one of their most successful programs invites professors and experts in various fields to host single- or multi-day lectures/workshops. A variety of outreach programs are an additional way in which residents are challenged to continuing growing intellectually. One is the weekly Read to Kids Program where retirees are transported to the local library to spend time reading with young children. Another example is Muffins with Meadowlark at a local daycare center. Once a month a bus load of seasoned residents join the preschool class to have breakfast, assist the children with their lessons, and share in crafts and singing. Residents find these programs to be extremely fulfilling. Some have indicated that it fills a void in their life because it is a substitute for time they would spend with their own grandchildren if they did not live so far away.

An even more successful program is the Volunteers Program. Volunteers have a wide variety of options to choose from including sitting on the board of direc- 
tors, participating in planning committees (e.g. arts or social events), and serving as hosts or tour guides for prospective new residents. Kay provided an excellent overview of the value of the Volunteers Program when she said, "[ The staff here] have a whole covey of people who have all kinds of skills. Some of them [residents] are perfectly content to sit down in the game room and visit, but most of $[u s]$ would like to be doing things. Now we have a strong volunteer program that gives us that opportunity". The Volunteers Program is a win-win. The program gives residents a sense of purpose and it supplements the staff, relieving them of some of the time they would have spent completing their duties.

An effective LPC also caters to individuals' physical needs. The staff not only offers exercise classes led by a professional physical therapist, but there are also hiking trails, a community garden, and a pond for outdoor enthusiasts. All these spaces and activities encourage residents to stay active physically.

It is important to note that although there is an events director who oversees the various activities, residents are encouraged to participate in the planning process and help organize or develop new programs that cater to peoples' wants and desires. Some residents have said that living in an LPC is like being on a cruise ship year-round. There are a wide variety of activities and programs for people at all stages of their life to stimulate residents' intellectual and physical growth.

\section{Conclusion}

At every major milestone throughout their life, the baby boom population has had a tremendous impact on American society. The boomers are notorious for expecting more in terms of their own achievement, happiness, and long-term well-being. As this seasoned cohort approaches old age, they are seeking out accommodations to spend the remaining years of their life. They want a place that not only meets their basic needs, but provides an enriching, high quality of life. While some are choosing to age in place, preliminary evidence suggests that an LPC provides the ideal, all-encompassing environment that meets baby boomers' demands. However, existing research has not consulted with retirees to determine what qualities they value in a retirement community. This article helps fill that gap in the literature.

Drawing upon the experience and insights of current residents in an LPC, it exposes what characteristics retirees see as adding value to their life and leading to a strong sense of community. The findings are particularly relevant and noteworthy as individuals, and their Adult Child Influencers (ACIs), decide what their best option is for the future. The results should also aid decision makers and planners in urban areas throughout the world (e.g. Japan, Australia, and New Zealand, as well as most of Europe) as they prepare for the impending wave of retirees.

First and foremost, for a retirement community to be successful in meeting the needs of today's older folks, the place must be imbued with a friendly, posi- 
tive attitude and can-do spirit. Modern retirees have little patience for obstacles or restrictions that limit what they can do. Instead, they want to live their life to the fullest. In their go-go years ( $<75$ years of age) retirees want boundless opportunities that enrich their life. As they transition into their slow-go (75 to 85 years of age) and no-go ( $>85$ years of age) years, they insist that administrators and staff create an environment that facilitates a continued positive attitude. The foundation of an effective LPC is one that preserves and protects the sanctity of one's individual autonomy.

Strongly correlated to a positive atmosphere is the desire for continued personal growth. Successful LPCs create space where people can continue to grow as individuals. This includes amenities that support and encourage both physical (e.g. exercise classes, aqua aerobics) and intellectual (e.g. seminars, workshops) growth. Residents explained to us that they feel more fulfilled when there are ample opportunities to explore and grow especially alongside other members of the community.

Equally important is an environment that encourages close relationships with others. Residents want and expect an atmosphere that encourages social interactions with stimulating social events, group outings, and shared activities. Nearly everyone we talked with indicated that the special relationships they have with others is what makes the place feel like home. This includes the relationship residents have with employees. One of the things the makes an LPC stand out is that staff are considered friends and confidants. The genuine, caring atmosphere is what makes life worth living for most residents.

According to the work of Thomas and Blanchard (2009), society has created the false notion that cares for the advanced aged is an either-or proposition. Either an individual is institutionalized in a long-term care facility where they wait to die, or they live out the remaining years of their life in their personal home. Our research reveals that LPCs are disrupting that dichotomy by focusing on providing individualized care in a setting that feels as comfortable as home. Under a single umbrella of care, LPCs offer a wide variety of support services. Residents indicated that one of the most important services is the highly trained professionals on campus who offer specialized treatment and support for a variety of conditions (e.g. physical therapy, memory loss, dementia, depression). Furthermore, having such services on a campus setting enables couples/partners to remain geographically proximate. Additionally, support groups (e.g. personal grief, Parkinson's) are an equally important service provided. Clearly, the spectrum of care and services helps to make residents feel happier, healthier, and more fulfilled.

At the end of the day, the sum total of all these elements is that an LPC generates a space where people have the ability to continue living a meaningful life. Ubiquitously shared among all the individuals we interviewed is the desire to lead a purpose-driven life. This is particularly true of older folks who are nearing the end of their life. They want to look back and think that their life held meaning. 


\section{Acknowledgements}

We sincerely thank the residents and administration of Meadowlark Hills Retirement Community for their time and assistance in completing this research project. Their insight was invaluable. We also thank the external reviewers.

\section{Conflicts of Interest}

The authors declare no conflicts of interest regarding the publication of this paper.

\section{References}

AARP (2012). The United States of Aging Survey. Washington, DC: American Association of Retired Persons.

https://www.aarp.org/content/dam/aarp/livable-communities/old-learn/research/the-u nited-states-of-aging-survey-2012-aarp.pdf

Advent Health (2019). The Importance of Interpersonal Relationships for Your Health. https://www.adventhealth.com/hospital/adventhealth-gordon/news/importance-interp ersonal-relationships-your-health

Apóstolo, J., Cardoso, L. A., Rosa, D. F. B., \& Paúl, C. (2014). The Effect of Cognitive Stimulation on Nursing Home Elders: A Randomized Controlled Trial. Journal of Nursing Scholarship, 46, 157-166. https://doi.org/10.1111/jnu.12072

Ayalon, L. \& Green, V. (2012). Social Ties in the Context of the Continuing Care Retirement Community. Qualitative Health Research, 26, 394-400. https://doi.org/10.1016/j.jaging.2012.05.001

Blunt, A. (2005). Cultural Geography: Cultural Geographies of Home. Progress in Human Geography, 29, 505-515. https://doi.org/10.1191/0309132505ph564pr

Bohle, P., Rawlings-Way, O., Finn, J., Ang, J., \& Kennedy, D. J. (2014). Housing Choice in Retirement: Community versus Separation. Housing Studies, 29, 108-127. https://doi.org/10.1080/02673037.2013.825693

Brodsky, A. E., \& Marx, C. M. (2001). Layers of Identity: Multiple Psychological Sense of Community within a Community Setting. Journal of Community Psychology, 29, 161-178. https://doi.org/10.1002/1520-6629(200103)29:2<161::AID-JCOP1011>3.0.CO;2-1

Colby, S. L., \& Ortman, J. M. (2014). The Baby Boom Cohort in the United States: 2012 to 2060. Current Population Reports, U.S. Bureau of the Census. https://www.census.gov/prod/2014pubs/p25-1141.pdf

Creswell, J. W. (2013). Qualitative Inquiry \& Research Design: Choosing Among Five Approaches. Los Angeles, CA: SAGE Publications.

Emirbayer, M., \& Mische, A. (1998). What Is Agency? American Journal of Sociology, 103, 962-1023. https://doi.org/10.1086/231294

Erickson, M. A., Dempster-McClain, D., Whitlow, C., \& Moen, P. (2000). Social Integration and the Move to Continuing Care Retirement Community. In K. Pillemer, P. Moen, P. Glasgow, \& N. Wethington (Eds.), Social Integration in the Second Half of Life (pp. 211-230). Baltimore, MD: Johns Hopkins University Press.

Fox, N., Norton, L, Rashap, A., Angelelli, J., Tellis-Nyak, V., Tellis-Nyak, M., Grant, L., Ransom, S., Dean, S., Beatty, S., Brostoski, D., \& Thomas, W. (2005). Well-Being: Beyond Quality of Life-The Metamorphosis of Eldercare. Manhattan, KS: Action Pact 
Press.

Frey, W. H., \& DeVol, R. C. (2000). America's Demography in the New Century: Aging Baby Boomers and New Immigrants as Major Players. Santa Monica, CA: Milken Institute.

Fusch, P. I., Fusch, G. E., \& Ness, L. R. (2017). How to Conduct a Mini-Ethnographic Case Study: A Guide for Novice Researchers. The Qualitative Report, 22, 923-941.

Gilleard, C., Hyde, M., \& Higgs, P. (2007). The Impact of Age, Place, Aging In Place, and Attachment to Place on the Well-Being of the Over 50s in England. Research on Aging, 29, 590-605. https://doi.org/10.1177/0164027507305730

Glynn, T. J. (1981). Psychological Sense of Community: Measurement and Application. Human Relations, 34, 789-818. https://doi.org/10.1177/001872678103400904

Harvard Health (2019). The Health Benefits of Strong Relationships. Boston, MA: Harvard Medical School.

http://www.health.harvard.edu/newsletter_article/the-health-benefits-of-strong-relatio nships

Hettler, W. (1976). The Six Dimensions of Wellness. National Wellness Center. https://cdn.ymaws.com/www.nationalwellness.org/resource/resmgr/pdfs/sixdimension sfactsheet.pdf

Jones, A. (2019). Nursing Home Horror Stories. Aging Care. http://www.agingcare.com/articles/nursing-homes-perceptions-and-realities-133358.htm

Kennedy, D. J., \& Coates, D. (2008). Retirement Village Resident Satisfaction in Australia: A Qualitative Enquiry. Journal of Housing for the Elderly, 22, 311-334. https://doi.org/10.1080/02763890802458403

Krout, J. A., \& Wethington, E. (2003). Residential Choices and Experiences of Older Adults: Pathways to Life Quality. New York: Springer Publishing Company.

Leary, M., O’Brien, C., Smith, J. L., Bihary, J., Basic, A., \& O’Connor, D. (2019). The Age Well Study: Comparing Wellness Outcomes in Life Plan Communities vs. The Community-at-Large. Institute on Aging.

http://www.matherlifewaysinstituteonaging.com/senior-living-professionals/free-indus try-information/age-well-study-report-2019/

Lecovich, E. (2014). Aging in Place: From Theory to Practice. Anthropological Notebooks, 20, 21-33.

Long, D. A., \& Perkins, D. D. (2003). Confirmatory Factor Analysis of the Sense of Community Index and Development of a Brief SCI. Journal of Community Psychology, 31, 279-296. https://doi.org/10.1002/jcop.10046

Marx, K. A., Burke, K. L., Gaines, J. M., Resnick, B., \& Parrish, J. M. (2011). Satisfaction with Your New Home: Advantages and Disadvantages to Living in a CCRC. Seniors Housing and Care Journal, 19, 83-96.

Mckenzie, M., \& Schweiger, C. (2018). Senior Living Trends. CliftonLarsonAllen. https://www.claconnect.com/resources/white-papers/2018/-/media/files/white-papers/ 2018-senior-living-trends-white-paper-cliftonlarsonallen-llp.pdf

McMillan, D. W., \& Chavis, D. M. (1986). Sense of Community: A Definition and Theory. Journal of Community Psychology, 14, 6-23. https://doi.org/10.1002/1520-6629(198601)14:1<6::AID-JCOP2290140103>3.0.CO;2-I

MetLife (2011). Market Survey of Long-Term Care Costs: The 2011 MetLife Market Survey of Nursing Homes, Assisted Living, Adult Day Services, and Home Care Costs. https://www.aarp.org/content/dam/aarp/livable-communities/old-learn/health/the-met 
life-market-survey-of-nursing-home-assisted-living-adult-day-services-and-home-care -costs-2011-aarp.pdf

Morley, J. E., Philpot, C. D., Gill, D., \& Berg-Weger, M. (2014). Meaningful Activities in the Nursing Home. Journal of the American Medical Directors Association, 15, 79-81. https://doi.org/10.1016/j.jamda.2013.11.022

Oswald, F., Jopp, D., Rott, C., \& Wahl, H. W. (2010). Is Aging In Place A Resource for or Risk to Life Satisfaction? The Gerontologist, 51, 238-250.

https://doi.org/10.1093/geront/gnq096

Qualls, S. H. (2019). What Social Relationships Can Do for Health. San Francisco, CA: American Society on Aging. http://www.asaging.org/blog/what-social-relationships-can-do-health

Roberts, A. R., \& Adams, K. B. (2018). Quality of Life Trajectories of Older Adults Living in Senior Housing. Research on Aging, 40, 511-534. https://doi.org/10.1177/0164027517713313

Senior Living (2019). Aging in Place-What Does Aging in Place Really Mean? Senior Living Organization. http://www.seniorliving.org/aging-in-place

Smith, J. S. (2018). Explorations in Place Attachment. London: Routledge. https://doi.org/10.4324/9781315189611

Steinberg, K. (2018). Easing Regulations May Do More Good Than Harm. Caring For the Ages. http://www.caringfortheages.com/article/S1526-4114(18)30002-7/fulltext https://doi.org/10.1016/j.carage.2018.01.003

Thomas, W. H., \& Blanchard, J. M. (2009). Moving Beyond Place: Aging in Community. Journal of the American Society on Aging, 33, 12-17.

USC (2019). The Value of Aging in Place. USC Leonard Davis School of Gerontology. https://gero.usc.edu/the-value-of-aging-in-place/ 